\title{
Editorial \\ Editorial Catalysts: Catalysis for the Removal of Gas-Phase Pollutants
}

\author{
Antonio Eduardo Palomares (D)
}

Instituto de Tecnología Química, Universitat Politècnica de València-Consejo Superior de Investigaciones Científicas, Avenida de los Naranjos s/n, 46022 Valencia, Spain; apalomar@iqn.upv.es

Citation: Palomares, A.E. Editorial Catalysts: Catalysis for the Removal of Gas-Phase Pollutants. Catalysts 2022, 12, 280. https://doi.org/ $10.3390 /$ catal12030280

Received: 10 February 2022 Accepted: 25 February 2022 Published: 2 March 2022

Publisher's Note: MDPI stays neutral with regard to jurisdictional claims in published maps and institutional affiliations.

Copyright: (C) 2022 by the author. Licensee MDPI, Basel, Switzerland. This article is an open access article distributed under the terms and conditions of the Creative Commons Attribution (CC BY) license (https:// creativecommons.org/licenses/by/ $4.0 /)$.
Air pollution is one of the greatest concerns affecting the world today. According to the World Health Organization (WHO), more than $80 \%$ of people living in urban areas are exposed to levels that exceed the WHO's recommended limits. While all regions of the world are affected, populations in low- and middle-income countries are the most impacted, and it is estimated that air pollution could cause 6 to 9 million premature deaths per year by 2060. In 2015, the WHO and the Organization for Economic Cooperation and Development (OECD) calculated that the economic cost of premature death and disability caused by air pollution in Europe is close to USD 1.6 trillion and will reach 1\% of the global gross domestic product (GDP) by 2060 [1].

Although, the emissions of the main pollutants have decreased in developed countries as result of more stringent emission limits in recent years, the global production of air pollutants has increased globally due to the discharge from newly industrialized countries. New technologies that contribute to the reduction of these emissions are a matter of urgent necessity. In this context, catalysis plays an important role in the control of pollutants, and many of the technologies that are used for air pollution abatement are based on the use of different catalytic systems. It is expected that the discovery and preparation of new materials and our understanding of the catalytic reaction mechanisms will result in the development of new catalytic technologies for the control of gas-phase pollutants.

We hope that the review article and the original research papers edited in this Special Issue will provide solutions to these challenges through a broad range of innovative ideas while covering many aspects of the catalytic removal of air pollutants.

Some of the main air pollutants that are produced by stationary and mobile sources are volatile organic compounds (VOCs), and a great deal of legislation calling for the control of these emissions has appeared in recent years. Catalytic or photocatalytic oxidation is one of the best available technologies (BAT) for the control of these pollutants [2] in the chemical industry. However, VOC emissions may come from different sources, and Koziel et al. [3] have shown that the gaseous emissions from manure may be controlled by means of photolysis and photocatalysis with deep UV by using $\mathrm{TiO}_{2}$ as a catalyst. They observed that the use of this catalyst resulted in a decrease in VOC emissions, removing up to $\sim 80 \%$ the odor produced by those compounds. Photocatalysts that are based on $\mathrm{TiO}_{2} / \mathrm{SiO}_{2}$ can be also used for the removal of other VOCs such as toluene. Rongshu et al. [4] have shown that the capacity of $\mathrm{TiO}_{2}$ semiconductors to degrade organic air pollutants with visible light can be improved by doping the $\mathrm{TiO}_{2} / \mathrm{SiO}_{2}$ photocatalyst with fluorine ions as they improve the absorbance of visible and ultraviolet radiation. The authors also determined that the presence of water and oxygen in effluents enhanced toluene oxidation due to the generation of hydroxyl and peroxy radicals, respectively.

Nevertheless, conventional catalytic oxidation is the preferred method for the control of VOC pollutants in industry. Cobalt-based catalysts can be used for this type of reaction, and Jirátova et al. [5] have shown that the radio frequency magnetron sputtering of cobalt on stainless-steel meshes can be used as a tool to prepare these catalysts as meshes. The catalysts that were prepared using this method minimized the internal diffusion of the 
reactants and the use of expensive active components. When using this type of catalyst, they obtained activity that was 20 times higher than when a pelletized commercial $\mathrm{Co}_{3} \mathrm{O}_{4}$ catalyst was used. These good results can be attributed to the small particle size of the cobalt oxides, as catalytic activity is related to the particle size of $\mathrm{Co}_{3} \mathrm{O}_{4}$, with the best results being obtained with smaller particle sizes.

Cobalt cerium oxide catalysts prepared using the sol-gel method can be also used for toluene combustion at low temperatures, as described by Chen et al. [6]. They studied the influence of the addition of different organic acids during catalyst preparation on the composition, structure, morphology, and catalytic performance of the metal oxides that were prepared. In this work, they indicated that the nature of the organic acid has a strong effect on the textural and physicochemical properties of the synthesized metal oxides and, consequently, the catalyst activity.

$\mathrm{Ni} / \mathrm{Co}$-mixed oxides derived from hydrotalcites are also active catalysts that can be used for toluene oxidation, as described by Yunfa et al. [7]. They designed a $\mathrm{NiCo}_{2} \mathrm{O}_{4} / \mathrm{NiO}$ nanocage with $3 \mathrm{D}$ hierarchical hollow structures. These materials presented high-valence cobalt ions in the catalyst surface due to the hierarchical nanostructures as well as adsorbed oxygen species and abundant medium-strength surface acid sites that played a key role in catalytic activity. The same author proposed the use of Cu-doped Mn/Ce catalysts supported on a novel porous ceramic membrane monolith for benzene combustion [8]. Porous ceramic membranes (PCMs) are considered to be an efficient hot gas filtration material in industrial systems. The authors showed that it was possible to functionalize the PCMs with Cu-doped Mn/Ce catalysts for the VOC abatement during dust elimination. The prepared catalytic PCMs exhibited high benzene oxidation activity and showed strong resistance to high humidity $\left(90 \mathrm{vol} . \%, 20^{\circ} \mathrm{C}\right)$ and long-term stability.

$\mathrm{PdCe}_{\mathrm{x}} \mathrm{Co}_{\mathrm{y}}$ catalysts have been also used to control benzene emissions at low temperatures. Lin et al. [9] showed that the application of an electric field promotes benzene oxidation over these catalysts. The introduction of the electric field could save Pd-loading in the catalysts while maintaining a high benzene conversion rate, as electric fields create more active oxygens. This promoted the formation of active sites on the catalyst surface.

In the broad group of VOCs, Cl-VOCs are probably the most dangerous pollutants to be treated. Three-dimensionally ordered macroporous $\mathrm{TiO}_{2}$-supported AuPd alloy catalysts were used for trichloroethylene (TCE) oxidation. Dai et al. [10] showed the high catalytic activity of some of these materials, obtaining a $\mathrm{T}_{90}$ of $400{ }^{\circ} \mathrm{C}$ at a space velocity of $20,000 \mathrm{~mL} /(\mathrm{g} \mathrm{h})$. They described how the supported alloys had better catalytic stability and moisture resistance than $\mathrm{Au}$ - or Pd-supported samples. Nevertheless, there was a partial and reversible deactivation that was induced by $\mathrm{H}_{2} \mathrm{O}$, while the deactivation that was induced by $\mathrm{CO}_{2}$ was irreversible.

An alternative to catalytic oxidation for the treatment of $\mathrm{Cl}-\mathrm{VOCs}$ is catalytic reduction. Gomez-Sainero et al. [11] studied the catalytic hydrodechlorination of dichloromethane (DCM). They used a Pd/C catalyst for this reaction, as it exhibited better catalytic activity. However, the catalyst showed significant deactivation during the reaction, which was ascribed to the formation of a new $\mathrm{PdC}_{\mathrm{x}}$ phase during the reaction. The carbon atoms that had been incorporated into Pd lattice came from the Cl-hydrocarbons that had been adsorbed on the metallic species, the transformation of which was promoted by the $\mathrm{HCl}$ that was derived from the reaction. Nevertheless, the catalyst could be regenerated via air flow treatment at $250{ }^{\circ} \mathrm{C}$, resulting in more than $80 \%$ of the initial DCM conversion to be recovered.

An alternative low-temperature treatment procedure that can be implemented to treat the VOCs that are produced by combustion engines is the use of hydrocarbon traps. Olsson [12] studied the influence of doping zeolite beta (BEA) with Fe, Pd, and La on the storage and release of propene and toluene. The results from the TPD experiments showed that adding $\mathrm{Pd}$ and $\mathrm{La}$ to zeolite had a positive effect on the release patterns of the hydrocarbons that were stored on the trapping material. The in situ DRIFTS results indicated that these elements provided H-BEA with additional hydrocarbon storage sites. 
$\mathrm{NO}$ and $\mathrm{NO}_{2}$, recognized as $\mathrm{NO}_{\mathrm{x}}$, are additionally important air pollutants that are necessary to control. The BAT for the control of these pollutants that is used in different industries $[2,13]$ is selective catalytic reduction (SCR) with ammonia. This system is very effective at high temperatures, but at temperatures lower than $200^{\circ} \mathrm{C}$, the efficiency of the commercial catalysts decreases drastically. To avoid this problem, Wang et al. [14] studied the promotion effect of Ti species in $\mathrm{MnO}_{\mathrm{x}}-\mathrm{FeO}_{\mathrm{x}} /$ Silicalite- 1 for low-temperature $\mathrm{NH}_{3}-\mathrm{SCR}$ reactions. The optimized catalyst demonstrated an increased $\mathrm{NO}_{\mathrm{x}}$ conversion efficiency of $20 \%$ below $150{ }^{\circ} \mathrm{C}$ with a space velocity of $18,000 \mathrm{~h}^{-1}$, something that could be attributed to the Ti species that were incorporated into the silicalite. They promoted the formation of Lewis acid sites on the surface of the catalyst that were linked to $\mathrm{Mn}^{4+}$, improving the denitration efficiency at low temperatures.

The activity of the catalysts used for $\mathrm{NO}_{\mathrm{x}}-\mathrm{SCR}$ also depends on the support used for the active sites, as it occurs in other similar reactions [15]. Palomares et al. [16] studied the influence of the support on the activity of the Mn-Fe catalysts used for this reaction. They showed that $\mathrm{Mn}$ and Fe have a synergic effect that enhances conversion at low temperatures, with this effect being related to the type of support selected. Catalyst performance depended on the acidity of the support and on the surface area, with the best results being obtained for $\mathrm{Mn}-\mathrm{Fe}$ catalyst supported on Beta zeolite.

One of the main drawbacks of the $\mathrm{NH}_{3}-\mathrm{SCR}$ reaction is the hydrothermal stability of the catalysts, which is mainly the case when zeolites are used. Wang et al. [17] studied the effect of copper precursors on the activity and hydrothermal stability of $\mathrm{Cu}^{\mathrm{II}}-\mathrm{SSZ}-13$ catalysts. They prepared a series of catalysts by means of an in situ hydrothermal method using different copper precursors and studied their evolution in the presence of simulated diesel vehicle exhaust. It was shown that the distribution of $\mathrm{Cu}$ species and the $\mathrm{Si} / \mathrm{Al}$ ratio determined the catalytic activity and the hydrothermal stability of the catalysts, with the best catalytic ability and hydrothermal stability being obtained with the catalyst prepared with $\mathrm{Cu}\left(\mathrm{NO}_{3}\right)_{2}$.

Olsson et al. studied the deactivation of the $\mathrm{Cu} / \mathrm{SSZ}-13$ catalyst that is commonly used for $\mathrm{NH}_{3}$-SCR by exposing it to $\mathrm{CO}, \mathrm{H}_{2}$, and $\mathrm{C}_{3} \mathrm{H}_{6}$ [18], and they proposed that the reason for the increased deactivation observed in mild rich conditions was the transformation of the $\mathrm{Cu}$ species. These centres evolved from active isolated $\mathrm{Cu}^{2+}$, balancing two negative charges of $\mathrm{Al}$ atoms in the zeolite framework, to inactive $[\mathrm{CuOH}]^{+}$connected to one $\mathrm{Al}$ atom together with the formation of $\mathrm{Cu}$ clusters.

Those catalysts are usually disposed on honeycomb structures for industrial use. $\mathrm{Li}$ et al. [19] studied the structure effect on the activity and strength of an industrial honeycomb catalyst derived from different Ti sources. They proposed a new honeycomb production process with both a filter cake (produced from the hydrothermal treatment of metatitanic acid) and industrial titanium dioxide as Ti sources with improved denitrification efficiency. They found a positive correlation between the honeycomb's strength and crystallinity using samples obtained from different sources.

As previously stated, the commercial procedure for reducing $\mathrm{NO}_{\mathrm{x}}$ in the presence of air is its reduction with ammonia (or urea). Nevertheless, the use of this compound has many drawbacks that are related to its toxicity and reactivity with the other molecules that can be present in the exhaust gases. For that reason, some researchers are working with other selective reductants, such as hydrocarbons. Zhou et al. [20] studied the selective catalytic reduction of nitric oxide with propylene over Fe/Beta catalysts under lean-burn conditions. The results showed that the preparation method had a significant influence on the composition and distribution of iron species and thus on the catalyst activity. The best results were obtained with the catalysts that were prepared by liquid ion exchange because this process resulted in the formation of more isolated $\mathrm{Fe}^{3+}$ species, that are more active during NO reduction. Nevertheless, there was a slight decrease in the activity after the hydrothermal aging of the catalyst due to the migration of isolated $\mathrm{Fe}^{3+}$ ions into oligomeric clusters and/or $\mathrm{Fe}_{2} \mathrm{O}_{3}$ nanoparticles. 
Mono and bimetallic Ag, Fe, and Ag-Fe systems exchanged in sodium mordenite zeolite were used by Kotolevich et al. [21] as catalysts in the NO reduction reaction. They studied the effect of the cation deposition order during $\mathrm{NO}$ reduction with $\mathrm{C}_{3} \mathrm{H}_{6} / \mathrm{CO}$ using catalysts based on AgFe systems supported on mordenite. They concluded that the exchange order of the Ag and Fe cations had a strong effect on the catalyst activity, as different centres were formed depending on the exchange order.

In absence of oxygen, $\mathrm{CO}$ can be also used to reduce NO. Baiker et al. [22] studied the structure and catalytic behavior of alumina-supported bimetallic Au-Rh nanoparticles during this reaction. They found that the $\mathrm{NO}$ conversion of $\mathrm{AuRh} / \mathrm{Al}_{2} \mathrm{O}_{3}$ shifted to lower temperatures as the Rh content increased, with the highest activity and highest $\mathrm{N}_{2}$ selectivity being achieved for the monometallic $\mathrm{Rh} / \mathrm{Al}_{2} \mathrm{O}_{3}$ catalyst. They also found that doping the catalyst with ceria favored catalyst activity as the surface population of metallic $\mathrm{Rh}$ sites, which were considered to be the most active centres, increased.

A commercial alternative to control $\mathrm{NO}_{x}$ emissions in lean-burn engines is the $\mathrm{NO}_{\mathrm{x}}$ storage-reduction (NSR) system. This system is based on the storage of the $\mathrm{NO}_{\mathrm{x}}$ as nitrates during the lean period and on the desorption and reduction in the $\mathrm{NO}_{\mathrm{x}}$ stored during the rich period. Cui et al. [23] studied the performance of $\mathrm{Mn}$-doped $\mathrm{MgAlO}_{\mathrm{x}}$-mixed oxides for low-temperature $\mathrm{NO}_{\mathrm{x}}$ storage and release. The $\mathrm{Mn}$-doped $\mathrm{MgAlO}_{\mathrm{x}}$ catalysts exhibited a high $\mathrm{NO}_{\mathrm{x}}$ storage capacity (NSC) at a low temperature range $\left(150-300{ }^{\circ} \mathrm{C}\right)$, which was related to an increased surface area, an improved reducibility, and to the presence of surface $\mathrm{Mn}^{3+}$. Additionally, the influence of $\mathrm{CO}_{2}$, soot, $\mathrm{H}_{2} \mathrm{O}$, and $\mathrm{SO}_{2}$ on the $\mathrm{NO}_{x}$ storage performance of the $\mathrm{Mn}$ catalyst was studied. The authors described the strong resistance that this catalyst had to poisoning.

$\mathrm{N}_{2} \mathrm{O}$ is another stable nitrogen oxide that is considered as a type of gas pollutant. The reactivity and the problems generated by this molecule are different from those of other nitrogen oxides, contributing to ozone layer depletion and the greenhouse effect. Maitarad et al. [24] studied the effect of water on photo-assisted nitrous oxide decomposition over oxotitanium porphyrin and proposed, using density functional theory calculations, a potential catalyst that was tolerant to water and oxygen because of its low activation barrier, water resistance, and easy regeneration.

The other important $\mathrm{N}$-air pollutant is $\mathrm{NH}_{3}$. Górecka et al. [25] studied the use of $\mathrm{Cu}$ $\mathrm{Mg}-\mathrm{Fe}-\mathrm{O}-(\mathrm{Ce})$ complex oxides as catalysts for the selective catalytic oxidation of ammonia to dinitrogen $\left(\mathrm{NH}_{3}-\mathrm{SCO}\right)$. They investigated the influence of the chemical composition, specifically focusing on the occurrence of spinel phases, copper loading, and impregnation by cerium, in catalyst activity. The authours observed that the oxides 2 were active at temperatures above $300{ }^{\circ} \mathrm{C}$ and had a high selectivity to $\mathrm{N}_{2}$. Catalysts containing a low copper amount and doped with Ce were slightly more active at lower temperatures than the non-impregnated samples. However, when an optimal amount of copper (12 wt.\%) was used, the presence of cerium did not affect any catalytic properties. On the other hand, copper overloading caused the phases to rearrange themselves, leading to a decrease in the catalytic activity.

Carbon oxides are another important group of pollutants. Controlling $\mathrm{CO}$ emissions is essential due to their toxicity and the fact that it can cause death in humans. Rangel et al. [26] studied low-temperature $\mathrm{CO}$ oxidation over $\mathrm{CeO}_{2} / \mathrm{Bi}_{2} \mathrm{Mo}_{1-\mathrm{x}} \mathrm{Ru}_{\mathrm{x}} \mathrm{O}_{6}$ and $\mathrm{Au}$ / $\mathrm{Bi}_{2} \mathrm{Mo}_{1-\mathrm{x}} \mathrm{Ru}_{\mathrm{x}} \mathrm{O}_{6}$ catalysts. The BiMoRu oxides were synthesized through a hydrothermal procedure under microwave heating. This procedure made the preparation of mixed oxides easy [27]. $\mathrm{CeO}_{2}$ was deposited on the mixed oxides using the wet impregnation method, while the incipient impregnation method was selected to deposit gold nanoparticles. The catalysts were characterized in depth, and the results showed that the best system was the $\mathrm{Au} / \mathrm{Bi}_{2} \mathrm{Mo}_{0.95} \mathrm{Ru}_{0.05} \mathrm{O}_{6}$ catalyst. It was shown that when using this material, $\mathrm{CO}$ oxidation started at $50{ }^{\circ} \mathrm{C}$ and reached $100 \%$ conversion at $186{ }^{\circ} \mathrm{C}$.

On the other hand, although the toxicity of $\mathrm{CO}_{2}$ is minimal, controlling it is necessary, as this is the main gas that is responsible for the greenhouse effect, and this is likely the most important challenge to be solved by humanity in the upcoming years. Wei Su 
et al. [28] present an interesting analysis of the research status of $\mathrm{CO}_{2}$ conversion technology using the bibliometric method. The influence of countries and institutions, journal article statistics, and other aspects were analysed, and future directions for this field of research are proposed. This study shows that a possible method that can be used for the treatment of this gas was to transform it into hydrocarbons. In this way, Martínez et al. [29] studied the use of nickel catalysts for $\mathrm{CO}_{2}$ methanation. The most outstanding results were obtained with nickel catalysts supported on $\mathrm{ZrO}_{2}$, which obtained $\mathrm{CO}_{2}$ conversions close to $60 \%$ and methane formation selectivity of $100 \%$.

The diversity of the contributions in this Special Issue reflects the plethora of research questions regarding the control of air pollutants. Controlling these pollutants is a necessity all over the world, and from the analysis of the different papers presented here, it is clear that catalysis will continue to be one of the most important process for the treatment of exhaust gases from different sources.

I would like to express my sincerest thanks to all of the authors for their valuable contributions, without which this Special Issue would not have been possible.

Funding: This research received no external funding.

Conflicts of Interest: The author declares no conflict of interest.

\section{References}

1. OECD. The Economic Consequences of Outdoor Air Pollution; OECD Publishing: Paris, France, 2016. [CrossRef]

2. European Commission, Joint Research Centre; Brinkmann, T.; Falcke, H.; Holbrook, S.; Sanalan, T.; Roth, J.; Sancho, L.D.; Clenahan, I.; López-Carretero, A.; Zerger, B.; et al. Best Available Techniques (BAT) Reference Document for the Production of Large Volume Organic Chemicals; Publications Office of the European Union: Luxembourg, 2017. [CrossRef]

3. Yang, X.; Koziel, J.A.; Laor, Y.; Zhu, W.; van Leeuwen, J.; Jenks, W.S.; Hoff, S.J.; Zimmerman, J.; Zhang, S.; Ravid, U.; et al. VOC Removal from Manure Gaseous Emissions with UV Photolysis and UV-TiO 2 Photocatalysis. Catalysts 2020, 10, 607. [CrossRef]

4. Qiu, L.; Wang, Y.; Li, H.; Cao, G.; Ouyang, F.; Zhu, R. Photocatalytic Oxidation of Toluene on Fluorine $\mathrm{Doped}_{\mathrm{TiO}} / \mathrm{SiO}_{2} \mathrm{Catalyst}$ Under Simulant Sunlight in a Flat Reactor. Catalysts 2018, 8, 596. [CrossRef]

5. Jirátová, K.; Perekrestov, R.; Dvořáková, M.; Balabánová, J.; Topka, P.; Koštejn, M.; Olejníček, J.; Čada, M.; Hubička, Z.; Kovanda, F. Cobalt Oxide Catalysts in the Form of Thin Films Prepared by Magnetron Sputtering on Stainless-Steel Meshes: Performance in Ethanol Oxidation. Catalysts 2019, 9, 806. [CrossRef]

6. Chen, J.; Lin, J.; Chen, J.; Wang, J. Effect of Small Molecular Organic Acids on the Structure and Catalytic Performance of Sol-Gel Prepared Cobalt Cerium Oxides towards Toluene Combustion. Catalysts 2019, 9, 483. [CrossRef]

7. Wang, D.; Li, S.; Du, Y.; Wu, X.; Chen, Y. Self-Templating Synthesis of 3D Hierarchical $\mathrm{NiCo}_{2} \mathrm{O}_{4} @ N i O$ Nanocage from Hydrotalcites for Toluene Oxidation. Catalysts 2019, 9, 352. [CrossRef]

8. Cuo, Z.; Wang, D.; Gong, Y.; Zhao, F.; Liu, H.; Chen, Y. A Novel Porous Ceramic Membrane Supported Monolithic Cu-Doped Mn-Ce Catalysts for Benzene Combustion. Catalysts 2019, 9, 652. [CrossRef]

9. Shen, F.; Li, K.; Xu, D.; Li, X.; Zhao, X.; Chen, T.; Zhan, R.; Lin, H. Electric Field Promoted Complete Oxidation of Benzene over $\mathrm{PdCe}_{\mathrm{x}} \mathrm{Co}_{\mathrm{y}}$ Catalysts at Low Temperature. Catalysts 2019, 9, 1071. [CrossRef]

10. Zhang, X.; Liu, Y.; Deng, J.; Zhang, K.; Yang, J.; Han, Z.; Dai, H. AuPd/3DOM TiO 2 Catalysts: Good Activity and Stability for the Oxidation of Trichloroethylene. Catalysts 2018, 8, 666. [CrossRef]

11. Liu, S.; Martin-Martinez, M.; Álvarez-Montero, M.A.; Arevalo-Bastante, A.; Rodriguez, J.J.; Gómez-Sainero, L.M. Recycling of Gas Phase Residual Dichloromethane by Hydrodechlorination: Regeneration of Deactivated Pd/C Catalysts. Catalysts 2019,9 , 733. [CrossRef]

12. Jonsson, R.; Woo, J.; Skoglundh, M.; Olsson, L. Zeolite Beta Doped with La, Fe, and Pd as a Hydrocarbon Trap. Catalysts 2020, 10, 173. [CrossRef]

13. European Commission, Joint Research Centre; Neuwahl, F.; Brinkmann, T.; Lecomte, T.; Pinasseau, A.; Delgado Sancho, L.; Canova, M.; Ferrería de la Fuente, J.F.; Jankov, I.; Roudier, S. Best Available Techniques (BAT) Reference Document for Large Combustion Plants; Publications Office of the European Union: Luxembourg, 2017. [CrossRef]

14. Gu, J.; Duan, R.; Chen, W.; Chen, Y.; Liu, L.; Wang, X. Promoting Effect of Ti Species in $\mathrm{MnO}_{\mathrm{x}}-\mathrm{FeO} \mathrm{O}_{\mathrm{x}} / \mathrm{Silicalite}-1$ for the Low-Temperature $\mathrm{NH}_{3}$-SCR Reaction. Catalysts 2020, 10, 566. [CrossRef]

15. Corma, A.; Franch, C.; Palomares, A.E. A study of different supports for the catalytic reduction of nitrates from natural water with a continuous reactor. Catal. Today 2011, 172, 90. [CrossRef]

16. López-Hernández, I.; Mengual, J.; Palomares, A.E. The Influence of the Support on the Activity of Mn-Fe Catalysts Used for the Selective Catalytic Reduction of $\mathrm{NO}_{\mathrm{x}}$ with Ammonia. Catalysts 2020, 10, 63. [CrossRef]

17. Wang, M.; Peng, Z.; Zhang, C.; Liu, M.; Han, L.; Hou, Y.; Huang, Z.; Wang, J.; Bao, W.; Chang, L. Effect of Copper Precursors on the Activity and Hydrothermal Stability of $\mathrm{Cu}^{\mathrm{II}}-\mathrm{SSZ}-13 \mathrm{NH}_{3}-\mathrm{SCR}$ Catalysts. Catalysts 2019, 9, 781. [CrossRef] 
18. Auvray, X.; Mihai, O.; Lundberg, B.; Olsson, L. Deactivation of $\mathrm{Cu} / \mathrm{SSZ}-13 \mathrm{NH}_{3}-\mathrm{SCR}$ Catalyst by Exposure to $\mathrm{CO}, \mathrm{H}_{2}$, and $\mathrm{C}_{3} \mathrm{H}_{6}$. Catalysts 2019, 9, 929. [CrossRef]

19. Li, Y.; Abubakar, A.; Huangfu, L.; Li, C.; Li, J.; Yu, J.; Gao, S. The Structure Effect on the Activity and Strength of an Industrial Honeycomb Catalyst Derived from Different Ti Sources. Catalysts 2020, 10, 42. [CrossRef]

20. Zhou, H.; Ge, M.; Zhao, H.; Wu, S.; Li, M.; Su, Y. Selective Catalytic Reduction of Nitric Oxide with Propylene over Fe/Beta Catalysts Under Lean-Burn Conditions. Catalysts 2019, 9, 205. [CrossRef]

21. Sánchez-López, P.; Kotolevich, Y.; Miridonov, S.; Chávez-Rivas, F.; Fuentes, S.; Petranovskii, V. Bimetallic AgFe Systems on Mordenite: Effect of Cation Deposition Order in the NO Reduction with $\mathrm{C}_{3} \mathrm{H}_{6} / \mathrm{CO}$. Catalysts 2019, 9, 58. [CrossRef]

22. Wang, X.; Wang, H.; Maeda, N.; Baiker, A. Structure and Catalytic Behavior of Alumina Supported Bimetallic Au-Rh Nanoparticles in the Reduction of NO by CO. Catalysts 2019, 9, 937. [CrossRef]

23. Cui, C.; Ma, J.; Wang, Z.; Liu, W.; Liu, W.; Wang, L. High Performance of Mn-Doped MgAlO ${ }_{x}$ Mixed Oxides for Low Temperature $\mathrm{NO}_{x}$ Storage and Release. Catalysts 2019, 9, 677. [CrossRef]

24. Maitarad, P.; Promarak, V.; Shi, L.; Namuangruk, S. Effect of Water Molecule on Photo-Assisted Nitrous Oxide Decomposition over Oxotitanium Porphyrin: A Theoretical Study. Catalysts 2020, 10, 157. [CrossRef]

25. Górecka, S.; Pacultová, K.; Górecki, K.; Smýkalová, A.; Pamin, K.; Obalová, L. Cu-Mg-Fe-O-(Ce) Complex Oxides as Catalysts of Selective Catalytic Oxidation of Ammonia to Dinitrogen ( $\left.\mathrm{NH}_{3}-\mathrm{SCO}\right)$. Catalysts 2020, 10, 153. [CrossRef]

26. González, E.E.; Rangel, R.; Lara, J.; Bartolo-Pérez, P.; Alvarado-Gil, J.J.; Galván, D.H.; García, R. $\left\{\mathrm{CeO}_{2} / \mathrm{Bi}_{2} \mathrm{Mo}_{1-x} \mathrm{Ru}_{x} \mathrm{O}_{6}\right\}$ and $\left\{\mathrm{Au} / \mathrm{Bi}_{2} \mathrm{Mo}_{1-x} \mathrm{RuxO}_{6}\right\}$ Catalysts for Low-Temperature CO Oxidation. Catalysts 2019, 9, 947. [CrossRef]

27. Ayala, A.; Fetter, G.; Palomares, A.E.; Bosch, P. CuNi/Al hydrotalcites synthesized in presence of microwave irradiation. Mater. Lett. 2011, 65, 1663. [CrossRef]

28. Xing, Y.; Ma, Z.; Su, W.; Wang, Q.; Wang, X.; Zhang, H. Analysis of Research Status of $\mathrm{CO}_{2}$ Conversion Technology Based on Bibliometrics. Catalysts 2020, 10, 370. [CrossRef]

29. Martínez, J.; Hernández, E.; Alfaro, S.; López Medina, R.; Valverde Aguilar, G.; Albiter, E.; Valenzuela, M.A. High Selectivity and Stability of Nickel Catalysts for $\mathrm{CO}_{2}$ Methanation: Support Effects. Catalysts 2019, 9, 24. [CrossRef] 